\title{
Ensino de Filosofia na educação infantil
}

Robson Gabioneta

Mestre em Filosofia pela Unicamp

\section{Resumo}

Neste texto relato minha experiência de um pouco mais de um mês como professor de Filosofia para o ensino infantil (alunos de 2 a 6 anos) de um colégio particular de Campinas. Antes de falar das aulas, introduzo os parâmetros que observei para prepará-las. Entre eles destaco o autoconhecimento, que constituiu o primeiro bloco de aulas no qual trabalhei. Com essa preocupação, escolhi alguns textos da história da Filosofia, entre eles a Apologia e o Alcebiades de Platão e a Hermenêutica do Sujeito de Michel Foucault. Palavras-chaves: Filosofia; Crianças; Autoconhecimento.

\begin{abstract}
This text is about my experience of a little more than one month as philosophy teacher in a private preschool (students between 2 and 6 years old) at Campinas. Before to describe the classes itself, I introduce the parameters in which it was based upon. Between those parameters, I point out the selfknowledge, which was the first part developed by me. With regards to this, I have chosen some texts of the Philosophy History to be worked, for example, Apology and Alcibiades by Plato and Hermeneutics of the Subject by Michel Foucault.
\end{abstract}

Keywords: Philosophy; Children; Self-knowledge. 


\section{Parâmetros para a criação das aulas}

partir das orientações que recebi e da observação do universo
escolar no qual estava inserido, julguei que havia cinco pontos
fundamentais os quais precisava levar em consideração quando fosse preparar e, posteriormente, apresentar as aulas. São eles: 1) o que o colégio chama de "pilares" da educação infantil, entre eles: automotivação, autoconhecimento, autocontrole, etc; 2) as disciplinas "normais" para essa faixa etária: Português e Matemática; 3) as disciplinas "estimuladoras": Inglês, Artes, Música, Educação Física; 4) as disciplinas que os alunos terão nos anos escolares seguintes: Geografia e História; 5) por fim, aquilo que seria fundamental para o desenvolvimento saudável de crianças de 2 a 6 anos ao terem 50 minutos de aula de Filosofia uma vez por semana. ${ }^{1}$

No que tange aos pilares educacionais, atentei, num primeiro momento, para o autoconhecimento. Já quanto às disciplinas normais, fui informado de que, no caso do Português, utiliza-se a "literatura clássica"; já na Matemática ensina-se o sistema de numeração e proporção. No caso da literatura já temos um problema: o que é clássico? Ou, e acho que esta segunda pergunta é mais produtiva que a primeira, qual o impacto de uma história produzida há alguns séculos na psique de uma criança do século XXI?² Quanto às disciplinas "estimuladoras", me concentrei, num primeiro momento, nas aulas de Música e de Educação Física.

Assim, a partir do repertório filosófico que me é mais próximo e daquilo que julguei que poderia minimamente contribuir para a formação

$1 \mathrm{O}$ colégio possui uma teoria educacional que é uma espécie de síntese das principais teorias educacionais contemporâneas. Consultei alguns deles: Piaget (1987) e Vigotsky (2002). Há outras atividades que são oferecidas para as crianças, principalmente aquelas que ficam o período inteiro no colégio, entre elas: taekwondo, balé, informática, capoeira. Para crianças de 2 a 5 anos, haviam entre 5 e 10 alunos por sala, para as crianças de 6 anos, entre 15 e 20 . No total, eram 18 salas.

2 Não vamos desenvolver esse ponto. Essa discussão é feita, entre outros, por Franz (2002).

Filosofia e Educação [RFE] - Volume 8, Número 2 - Campinas, SP

Junho-Setembro de 2016 - ISSN 1984-9605 - p. 254-269 
dos alunos em questão, os temas que cogitei trabalhar em sala de aula foram: o conhecimento de si, do outro, da família e da sociedade; os sentimentos e os pensamentos; a amizade e o amor; a imitação e a representação; a cultura, a escrita e a notação musical; a dança e o corpo; a História e a Geografia; o tempo e o espaço; o sentido da vida e a morte; a memória e a escola.

Neste texto, me concentrarei no primeiro ponto, o conhecimento de si a partir do outro, isso pensando na família e na sociedade.

\section{Descrição das aulas}

$1^{\mathrm{a}}$ aula - apresentação do professor e aproximação dos amigos ${ }^{3}$

Perguntei: “O que é conhecer alguém? Se eu apenas olhar para o rosto de alguém, eu consigo saber o nome dessa pessoa? E se eu souber apenas o nome dela, eu sei onde ela mora? Eu sei quem são seus pais? Ou o que ela gosta ou o que ela não gosta? E se eu soubesse essas coisas, eu poderia saber o que ela já fez na vida, o que ela já estudou, com quem ela conversou?"

Depois, continuei: "Conhecer uma pessoa - e podemos inicialmente falar que tudo é mais ou menos assim - é algo que demora. Não conhecemos a pessoa de um dia para o outro. O conhecimento é algo lento. E, além disso, as pessoas mudam e, às vezes, o conhecimento que temos dela torna-se obsoleto. Além das pessoas, há, aqui na escola, muitas coisas para conhecer, os professores vão apresentar para vocês um monte de coisas: o Português, a Matemática, a Educação Física, o Inglês, a Música, as Artes, o sentimento e o pensamento. Em cada uma dessas coisas há muitas

3 Colocarei entre aspas a reprodução daquilo que falei às crianças e/ou daquilo que os alunos me disseram.

Filosofia e Educação [RFE] - Volume 8, Número 2 - Campinas, SP Junho-Setembro de 2016 - ISSN 1984-9605 - p. 254-269 
outras a serem aprendidas, por isso, dia após dia vamos aprender um pouco de cada coisa."

Depois dessa introdução, falei novamente o meu nome e alguns dos apelidos que tive ao longo da vida. Em seguida pedi para cada um ir ao centro e falar o nome. Adiantei que iria perguntar depois qual o nome do amigo; por isso, pedi para eles ouvirem com atenção o nome. Pedi para o aluno falar as variações do seu nome. ${ }^{4}$ Depois escolhi um aluno e tampei seus olhos, pedindo então para que o outro aluno falasse da sua antiga escola e/ou sobre sua família, de modo que o primeiro deveria adivinhar o nome do segundo. ${ }^{5}$

$2^{\mathrm{a}}$ aula - reflexão: ver-se no olho do amigo

Usando o final do diálogo Alcebíades de Platão, pedi para os alunos ficarem um de frente para o outro e se olharem nos olhos. Cada criança deveria se ver no olho do colega de sala. Feita a dinâmica, sentamos em roda para conversar sobre a experiência de se ver no olho do amigo. A pergunta inicial foi: “onde mais podemos nos ver?" As respostas foram rápidas: no espelho. ${ }^{6}$ Perguntei: "porque olhamos no espelho?" "Para nos ver", responderam os alunos. Acrescentei: "usamos os espelhos para ver aquilo que sem ele não conseguiríamos. Por exemplo, a orelha, o nariz, a boca e os próprios olhos." Em seguida, li o texto em questão:

\footnotetext{
4 Usei aqui o Crátilo de Platão para pensar as formações do nome. Tentei inventar apelidos amáveis que poderiam rimar ou combinar com o nome, tomando, mesmo assim, a precaução de perguntar se aquele apelido agradava a criança e, para aquelas que ainda assim não gostavam da brincadeira, pedi desculpas.

5 Com essa atividade, visei verificar o quão próxima era uma criança da outra. Desse modo, penso ter trabalhado com a percepção e com a memória, temas importantes para uma criança viver no século XXI. Repeti essa atividade um mês depois e percebi que, pelo convívio escolar, elas já eram capazes de reconhecer a voz do colega de sala.

6 Ajudou o fato de todas as salas possuírem espelhos. Um aluno disse que quando olha no olho de alguém vê a sua alma.
} 
Sócrates - Repara se a inscrição falasse aos olhos como fala ao homem e dissesse: conhece-te a ti mesmo, não concluiríamos que os mandava olharem para uma coisa onde pudessem ver-se?

Alcebíades - É evidente

$\mathrm{S}$ - Procuremos essa coisa onde pudéssemos ver-nos e vê-la.

A - Os espelhos e coisas semelhantes.

$\mathrm{S}$ - Muito bem; e não há nos olhos um pequeno local que dá o mesmo efeito de um espelho?

A - Há.

$\mathrm{S}$ - Sempre que examinas um olho vês a tua imagem na pequenina parte que tem nome com o sentido de boneca, por ser a imagem de quem se vê nela.

A-Assim é.

S - Um olho, para se ver em outro, há de olhar para essa parte que é a mais bela e capaz de ver.

A - Não há dúvida.

$\mathrm{S}$ - Se olhasse para outra parte do corpo ou para qualquer objeto, a não ser que fosse semelhante àquela parte do olho, não se veria.

A - Tens razão.

S - Um olho que queira ver-se tem de olhar para outro; e na parte onde reside toda a sua virtude, isto é, a visão.

A - Certamente

S - E a alma, para ver-se, não terá igualmente de olhar para a alma e justamente para onde reside a virtude, que é a sabedoria? Ou olhar para outra coisa ainda mais nobre, com que a alma de certo modo se parece?

A - Deve ser Sócrates. 
S - E haverá na alma parte mais divina do que aquela onde residem a ciência e a sabedoria?

Como podemos ver no texto, Platão pretende que o conhecimento do indivíduo passe pelo conhecimento produzido com o outro, ou melhor, os indivíduos, para se conhecerem, devem produzir juntos algo que suas almas possuem em comum e, a partir do resultado, ambos podem ser conhecidos. Não foi esse nosso objetivo. O que pretendíamos mostrar para os alunos e, por isso, insistimos nas aulas seguintes, era que muitas vezes as posturas dos amigos dependem das nossas atitudes, ou melhor, nossas atitudes são refletidas nas ações dos amigos. Desse modo, "quando um amigo brinca, briga, conversa com você, você participa dessa brinca-briga-conversa".7

$3^{\mathrm{a}}$ aula - conhecimento das pessoas

Voltando a falar de conhecimento, perguntei: "Vocês conhecem o amigo ao lado? Conhecer o amigo é apenas saber o seu nome? É saber onde ele mora? É conhecer seus pais? E vocês, conhecem todos da sua família? Conhecem seus quatro avós? Vocês sabem o que eles fizeram na vida? Vocês sabem como eles sustentaram seus pais quando seus pais eram como vocês? Vocês sabem suas histórias? Bom, se não sabe, fica uma pequena lição de casa: perguntar para seus avós o que eles fizeram durante suas vidas.”

7 Com a dinâmica miramos a consciência das ações, passivas e ativas, nas quais estamos todos envolvidos cotidianamente quando convivemos. Para nós, não existe ação individual, todas as ações formam o complexo ação-reação, desse modo entendemos reação também como ação. Com os alunos de 6 anos apresentamos a reflexão do Antônio Vieira no Sermão da sexagésima. Nela o padre diz que, para o homem se ver a si mesmo, precisa de olhos, de espelho e de luz. Com isso, mostramos uma das formas de apropriação das ideias: a paródia.

Filosofia e Educação [RFE] - Volume 8, Número 2 - Campinas, SP Junho-Setembro de 2016 - ISSN 1984-9605 - p. 254-269 
"E seus professores, vocês conhecem? E eu, vocês conhecem?" Outra coisa que eu queria falar de mim é que meu pai morreu. E quando eu tenho saudade dele, canto a música Naquela mesa de Sérgio Bittencourt. Se vocês quiserem, quando vocês sentirem saudades dos seus avós, vocês podem também cantá-la." Falei para eles que quando eu canto o trecho que diz "naquela mesa está faltando ele", lembro-me da casa da minha mãe alguns anos depois da morte do meu pai. ${ }^{10}$ Outra música semelhante é Além do espelho, de João Nogueira. Com ela, retomei a aula anterior, porém, essa música apresenta um adulto que, quando olha seu próprio olho no espelho, vê o seu pai e também o seu filho. ${ }^{11}$ Em seguida, cantei a música Deus me proteja de mim, do Chico Cesar. Canto essa música algumas vezes, principalmente quando penso nas relações que tenho com as pessoas e na imprevisibilidade dos caminhos que percorro e percorri. Desse modo, apresentei para os alunos a noção grega do acaso.

Por fim, falei que para conhecer as pessoas pode-se imitá-las. Então apresentei algumas coisas de que gosto e/ou a respeito das quais tenho curiosidade e pedi para eles me imitarem. Entre elas, a capoeira, a catira, o samba. ${ }^{12}$

8 Apresentei-me a partir de algumas atividades que já realizei, como eletricista, vendedor de ar-condicionado e professor de Filosofia para ensino médio.

9 Alguns alunos falaram que queriam aprender a música. Outros falaram que estavam com saudades dos seus pais.

10 Trabalho aqui com o conceito de Katarsis que Aristóteles apresentou na Poética.

11 Perguntei nas turmas de alunos mais velhos o que significava o medo do espelho se quebrar. Alguns responderam que o medo era perder a relação com a família.

12 Essa aula, em especial, contém um grande número de temas: as atividades profissionais que o adultos exercem, a relação entre pais e filhos, a morte, os gostos pessoais, a cultura. Todos eles merecem atenção e desenvolvimento, no caso desse texto isso não será possível, porém vamos indicar uma possível continuação: o professor pode apresentar o espetáculo Café com queijo realizado pelo grupo de pesquisa teatral da Unicamp, o LUME. No espetáculo e também nos livros e DVDs feitos pelo grupo, há o conceito mimesis. Esse conceito pode ser usado para se discutir: cultura, história, arte, entre outros. Voltando ao relato da aula perguntei para algumas salas se eles queriam conhecer alguma outra coisa de mim, uma aluna disse que queria conhecer minha mãe.

Filosofia e Educação [RFE] - Volume 8, Número 2 - Campinas, SP Junho-Setembro de 2016 - ISSN 1984-9605 - p. 254-269 
$4^{\mathrm{a}}$ aula - conhecimento do corpo e noção de parte e todo

"Na aula de hoje vamos conhecer um pouco da gente mesmo, ou seja, vamos conhecer um pouco do nosso corpo. ${ }^{13} \mathrm{E}$ faremos isso pensando na função de cada parte do corpo:

- Pé - nos liga ao chão; ${ }^{14}$

- Joelho - interliga o pé a coxa;

- Coxa - é o lugar onde ficam os músculos que nos permite andar;

- Na região da bacia - temos os órgãos sexuais e excretores. Estes últimos eliminam aquilo que o corpo não consegue absorver;

- Tronco - temos um monte de órgãos:

○ Coração - bombeia sangue ao corpo;

○ Pulmão - bombeia ar ao corpo;

○ Estômago - digere os alimentos;

○ Intestino - absorve os alimentos;

○ E outros: fígado, pâncreas, vesículas, etc.

- Mão - que nos permite manipular as coisas;

- Braço - é onde ficam os músculos que usamos para mexer a mão;

- Cotovelo - interliga a mão ao braço, como o joelho;

- Rosto - temos alguns órgãos:

○ Olhos - vemos;

○ Boca - comemos e falamos;

○ Ouvido - ouvimos;

13 Nas turmas de alunos mais velhos disse que há quem ache que somos um composto de corpo e alma e há quem acredite que também a alma é corpo, por isso seríamos só corpo. Em geral, houve uma confusão entre os alunos.

$14 \mathrm{Na}$ verdade, antes de falar a função que me parece ser de cada órgão, perguntei a eles qual era a função de cada parte do corpo. No caso do pé, muitos falaram que a função dele é andar.

Filosofia e Educação [RFE] - Volume 8, Número 2 - Campinas, SP Junho-Setembro de 2016 - ISSN 1984-9605 - p. 254-269 
- Nariz - cheiramos e respiramos;

- Cérebro - além de guardar as sensações, ele coordena as mãos e os pés. Ele não controla os órgãos internos, mas precisa contribuir para o funcionamento deles. Por exemplo: quando a bexiga está cheia, ela avisa o cérebro. $\mathrm{O}$ cérebro então ordena aos olhos para procurar um banheiro. Depois que os olhos acham o banheiro, o cérebro ordena aos pés para se dirigir a ele. Quando estamos com fome, nosso corpo inteiro avisa o cérebro para procurar comida. E assim por diante. ${ }^{15}$

Apesar de eles serem diferentes entre si, formam um todo. Inclusive é por ser diferentes que eles formam um todo. "Imagine o que aconteceria se fossemos só perna? Viveríamos correndo. Ou se tivéssemos mais bocas? Comeríamos mais do que comemos hoje. ${ }^{16}$ Cada órgão faz sua função para que no final o corpo funcione bem, permaneça vivo de modo saudável."

"Vamos desenhar um corpo? Cada um desenhe a parte do corpo que quiser. Fique à vontade, pode desenhar o pé, a orelha, o coração, qualquer parte.” Depois que todas as crianças desenharam, pedi o desenho de cada uma para formar um corpo. Assim, começando pelas extremidades, fui colocando fita crepe para formar esse corpo coletivo. Nas partes que não foram desenhadas coloquei uma folha em branco. Depois de montado o desenho, conversei sobre o resultado: “o que criamos? Este corpo é

15 Pode-se exercitar a descrição de outras situações dessa natureza. Exemplo: sede, fome, vontade de correr, frio, calor, transpiração, etc. Notei que os alunos que trabalhei desconhecem totalmente o funcionamento dos órgãos internos.

16 Pode-se pedir o seguinte exercício: o que aconteceria se tivéssemos mais um órgão, por exemplo: se tivéssemos mais um coração, mais um pulmão, mais um nariz, etc. Houve uma sala onde os alunos inventaram uma comunicação entre as partes do corpo, uma mão falou com o joelho, um braço falou com a perna. Estimulei outras variações.

Filosofia e Educação [RFE] - Volume 8, Número 2 - Campinas, SP Junho-Setembro de 2016 - ISSN 1984-9605 - p. 254-269 
possível $?^{17}$ Não pensamos em cada um fazer uma parte, então vamos fazer isso agora?" Assim, coloquei as folhas juntas no chão e fiz os limites do corpo. Depois dei uma folha para cada para terminar o desenho.

Enfatizei a questão de que cabe ao professor a coordenação do grupo. Uma espécie de cérebro do grupo. É claro que cada "órgão", cada aluno, pode e deve participar das decisões dando sugestões, falando o que está sentindo, mas cabe ao professor conduzir os alunos para que todos tenhamos nossas necessidades supridas, isto é, possamos crescer-aprenderdesenvolver de modo saudável para si e com os outros.

$5^{\mathrm{a}}$ aula - conhecimento do corpo: automassagem

"Como estamos falando do corpo podemos cantar a música da minhoquinha: 'fui no mercado comprar café / e uma formiguinha subiu no meu pé / e eu sacudi, sacudi, sacudi / mas a formiguinha não parava de subir" (e assim por diante). Voltei a falar acerca da fisiologia, do funcionamento do corpo. Perguntei então: "quando sentimos fome, qual a parte do corpo que avisa o cérebro?" Muitos responderam: "o estômago". Perguntei então se é só o estômago que precisava de comida. Todos concluíram que o corpo todo precisa de comida. Logo, todo o corpo avisa o cérebro de que precisa de alimentos. E também de água, de ar. "E o sono, quem avisa o cérebro que estamos precisando dormir? E a transpiração?"18

Depois, em roda, pedi para os alunos tocarem o próprio corpo, começando pelo pé, depois para o tornozelo e parando um pouco na

17 A grande maioria das crianças fez o corpo inteiro. Muitos fizeram o cérebro. Alguns fizeram o coração, outros fizeram duas ou três partes. Pouquíssimos, para surpresa das professoras e da coordenadora, desenharam órgãos sexuais.

18 Uma aluna, quando comecei a falar do corpo, perguntou se aquilo era aula de Filosofia ou de medicina. Disse a ela que o corpo não é exclusividade da medicina e que todas as disciplinas devem falar sobre tudo, ainda que cada disciplina estude algo em particular, sua "especialidade", todas as matérias escolares precisam do conhecimento de todas. Depois ela me disse que iria fazer medicina.

Filosofia e Educação [RFE] - Volume 8, Número 2 - Campinas, SP Junho-Setembro de 2016 - ISSN 1984-9605 - p. 254-269 
panturrilha. Com isso, pedi para eles perceberem a diferença do músculo contraído do músculo relaxado, e também pedi para eles atenção no controle do músculo. Fiz isso também com os músculos da coxa, do braço, do antebraço e das costas. Os músculos da costa, em especial, são mais difíceis de serem tocados, então pedi para que, em duplas, percebessem os músculos dos amigos. ${ }^{19}$

$6^{\mathrm{a}}$ aula - quando o não saber torna-se saber

Li para os alunos um trecho a Apologia de Platão:

Sócrates - Vocês conhecem Querefonte, eu presumo. Ele era meu companheiro desde moço e companheiro também de vocês [...]. Pois certa vez, indo a Delfos, se atreveu a solicitar esta adivinhação: perguntou se alguém seria mais sábio que eu. Retrucou então a Pítia que não havia ninguém mais sábio. [...]

Examinem por que razão estou dizendo isso; é que vou lhes ensinar de onde surgiu a calúnia contra mim. Depois de ouvir aquelas palavras, fiquei refletindo assim: "O que é que o deus está dizendo, e o que é que está falando por enigma? Pois bem sei comigo mesmo que não sou sábio - nem muito, nem pouco. O que ele está dizendo então, ao afirmar que sou o mais sábio? Certamente não está mentindo, pois para ele não é algo lícito.” E depois de ficar muito tempo em aporia (o que será que ele está

19 Percebi que na primeira atividade, automassagem, eles se dispersaram com facilidade. Alguns precisaram da minha ajuda para localizar os músculos e a diferença entre contração e relaxamento muscular. Também eles tiveram dificuldade de localizar os músculos nas costas dos amigos. Essas atividades poderiam ser desdobradas em outras como: em duplas, os alunos podem fazer massagens nos pés, nas mãos, nos braços; alguém no centro da roda recebe massagem de todos. Pensamos essa aula a partir do mote 'conhecimento de si' de Foucault.

Filosofia e Educação [RFE] - Volume 8, Número 2 - Campinas, SP Junho-Setembro de 2016 - ISSN 1984-9605 - p. 254-269 
dizendo?), a muito custo me voltei para uma investigação disso, da seguinte maneira: fui até um dos que parecem ser sábio, porque, se havia um lugar, era esse onde eu refutaria o adivinhado e mostraria ao oráculo - "este aqui é mais sábio do que eu, e você afirmava que era eu...”

Ao examinar bem então esse homem (não preciso absolutamente chamá-lo pelo nome; era um dos envolvidos com a política esse junto ao qual tive, examinando-o, esta impressão) e ao dialogar com ele, varões atenienses, me pareceu que parecia ser sábio para muitos outros homens e principalmente para si próprio, mas que não era. Em seguida, fiquei tentando lhe mostrar que ele pensava ser sábio, mas que não era. A partir daí me tornei odioso a ele e a muitos dos circunstantes e, indo embora, fiquei então raciocinando comigo mesmo "Sou sim mais sábio que esse homem; pois corremos o risco de não saber, nenhum dois, nada de belo nem de bom, mas enquanto ele pensa saber algo, não sabendo, eu, assim como não sei mesmo, também não penso saber... É provável, portanto, que eu seja mais sábio que ele numa pequena coisa, precisamente nesta: porque aquilo que não sei, também não penso saber.”

O texto é riquíssimo e os encaminhamentos poderiam ser diversos, como por exemplo: a mitologia grega e a consulta aos oráculos; a mudança de concepção de mentira empregada por Platão contrapondo-se, por exemplo, à de Hesíodo; a mudança da noção de sabedoria da Grécia arcaica para a Grécia clássica; além, é claro, do julgamento de Sócrates e sua posterior condenação. Mas o que enfatizei foi a constatação de Sócrates: ao reconhecer-se como não sábio, descobriu um saber superior ao de outros - 
no trecho fala-se do político, mas na aula falei também da conversa que Sócrates teve com um poeta e um artesão, conforme continuação do texto que ou julgam-se a si próprios sábios ou são reputados como sábios pela cidade. $^{20}$

Pensando em Foucault, li, ainda na Apologia, um trecho à frente. A questão que me interessou foi o deslocamento feito pelo filósofo francês do questionamento de Sócrates para o "cuidado de si".

$$
\begin{aligned}
& \text { Sócrates - Varões atenienses [...] receio não parar de } \\
& \text { filosofar e a vocês advertir e mostrar [...], falando } \\
& \text { daquele jeito a que estou habituado - "melhor dos } \\
& \text { homens, você, sendo um ateniense, não sente vergonha } \\
& \text { de militar em favor do dinheiro (a fim de possuir o } \\
& \text { máximo possível), e da fama e da honra, mas em favor da } \\
& \text { reflexão, da verdade e da alma (a fim de ser a melhor } \\
& \text { possível) não militar nem se preocupar?" E se algum de } \\
& \text { vocês quiser discutir e disser que milita, não o liberarei } \\
& \text { de imediato nem me afastarei, mas vou interrogá-lo, e } \\
& \text { inspecioná-lo, e refutá-lo. E se me parecer não ter } \\
& \text { adquirido a virtude - mas dizer que sim -, vou reprová-lo } \\
& \text { por considerar de menos o digno do máximo, e o mais } \\
& \text { banal, demais. [...] Nenhuma outra coisa faço enquanto } \\
& \text { circulo a não ser persuadir, tanto os mais jovens quanto } \\
& \text { os mais velhos dentre vocês, a não militar em favor nem } \\
& \text { do corpo nem do dinheiro - não antes (nem com a mesma } \\
& \text { intensidade) que em favor da alma, a fim de ser a melhor } \\
& \text { possível -, e vou dizendo que não surge do dinheiro a }
\end{aligned}
$$

20 As referências e os comentários desse trecho da Apologia são bem extensos. Há dois interessantes comentários recentes sobre esse texto: Roberto Bolzani Filho (2013) e Fabio Amorim Mattos Junior (2013).

Filosofia e Educação [RFE] - Volume 8, Número 2 - Campinas, SP Junho-Setembro de 2016 - ISSN 1984-9605 - p. 254-269 
virtude, mas da virtude o dinheiro, e todos os demais bens humanos, públicos e privados.

Foucault, ao comentar esse trecho, apresenta e desenvolve a máxima: "cuide de si próprio". Para ele, o "cuidar de si" foi algo que sofreu um processo de mudança de significado, do positivo para o negativo. Assim, considerando esse texto, pretendi que os alunos tenham a clareza de que algumas pessoas "cuidam" deles. Entre elas: os pais, os avós, as que estão na escola. E, pensando na relação familiar, propus como exercício que eles perguntassem para seus pais e seus avós como eles cuidam de si próprios. ${ }^{21}$

\section{Considerações finais}

Pensamos que a Filosofia é, acima de tudo, uma disciplina pedagógica e, assim como as outras disciplinas, tem a missão de conduzir as crianças nesse processo de entrada no mundo. Os temas aqui apresentados - o conhecimento de si e do outro, o funcionamento das partes do corpo num todo complexo e outros apenas mencionados: o uso que fazemos dos símbolos para representar as coisas e assim construir nossa linguagem, e, a partir do uso dela, comunicarmos as novas gerações o que ocorreu antes delas nascerem - são temas que desde Protágoras, talvez nosso primeiro pedagogo, sempre preocuparam os filósofos. Platão, em especial, preocupou-se com esses temas e com outros, como: o uso da mitologia para ensinar a língua grega às crianças (no Protágoras, na República, entre outros), a relação entre pais e filhos (discutida, entre outros, no Laques, no

21 Outra atividade que poderia ser feita é: "vamos fazer como Sócrates e procurar sábios, questionando seus saberes?" Num primeiro momento, os alunos podem conversar com seus pais e parentes, mas isso poderia ser estendido para os vizinhos e outros próximos. A pesquisa inicial pode ser: "o que o senhor sabe? E como conseguiu esse saber?"

Filosofia e Educação [RFE] - Volume 8, Número 2 - Campinas, SP Junho-Setembro de 2016 - ISSN 1984-9605 - p. 254-269 
Lísis e no Protágoras), a participação política na cidade (apresentada principalmente no Protágoras, no Alcebiades e na República) ${ }^{22}$.

Enfim, é hora de os amantes da Filosofia atuarem mais na educação infantil e ajudarem as(os) nossas(os) pedagogas(os) nessa complexa mas fundamental tarefa de cuidar-educar-amar as nossas crianças.

\section{Referências bibliográficas}

BOLZANI, Roberto Filho. Ensaios sobre Platão. São Paulo: USP, 2013 (tese de livre docência).

FRANZ, Marie-Louise Von. A sombra e o mal nos contos de Fada. Trad. Maria C. Penteado Kujawski. São Paulo: Paulus, 2002.

FOUCAULT, Michel. A hermenêutica do sujeito. Trad. Marcio Alves da Fonseca. São Paulo: Martins Fontes, 2004.

GABIONETA, R. Um estudo sobre o sofista Protágoras nos diálogos de Platão. Campinas: Unicamp, 2004 (Dissertação de Mestrado em Filosofia). MATOS JUNIOR, Fabio Amorim. O tratamento da impiedade no contexto dramático do 'Eutifron': um pastiche das 'Nuvens' como extensão da ‘Apologia de Sócrates'. Campinas: Unicamp, 2013 (tese de doutorado).

PIAGET, Jean. O nascimento da inteligência na criança. Trad. Alvaro Cabral. Rio de Janeiro: Guanabara, 1987.

PLATÃO. Apologia de Sócrates. Trad. Andre Malta. São Paulo: L\&PM, 2008 .

. Alcebiades. Trad. Carlos Alberto Nunes. Belém: Ed. da Universidade do Pará, 1973.

. Crátilo. Trad. Carlos Alberto Nunes. Belém: Ed. da Universidade do Pará, 1973.

22 Pretendemos em breve desenvolver esses outros temas num próximo artigo.

Filosofia e Educação [RFE] - Volume 8, Número 2 - Campinas, SP Junho-Setembro de 2016 - ISSN 1984-9605 - p. 254-269 
VIGOTSKY, L. S.. A formação da mente: o desenvolvimento dos processos psicológicos superiores. Trad. Jose Cipolla Neto. São Paulo: Martins Fontes, 2002. 